\title{
CrimRxiv
}

\section{Identifying the Culprit: Assessing Eyewitness Identification}

National Research Council

Published on: Jul 01, 2014

DOI: $10.21428 / c b 6 a b 371.9 b 235999$

License: Creative Commons Attribution 4.0 International License (CC-BY 4.0). 
